\title{
Rigler triad in gallstone ileus
}

\section{Dessie Roothans BM, Sébastien Anguille MD}

Competing interests: None declared.

This article has been peer reviewed.

Affiliations: From the Department of Internal Medicine (Roothans, Anguille), Antwerp University Hospital, Antwerp, Belgium

Correspondence to: Sébastien Anguille, sebastien.anguille@uza.be

CMAJ 2013. DOI:10.1503 /cmaj.121432
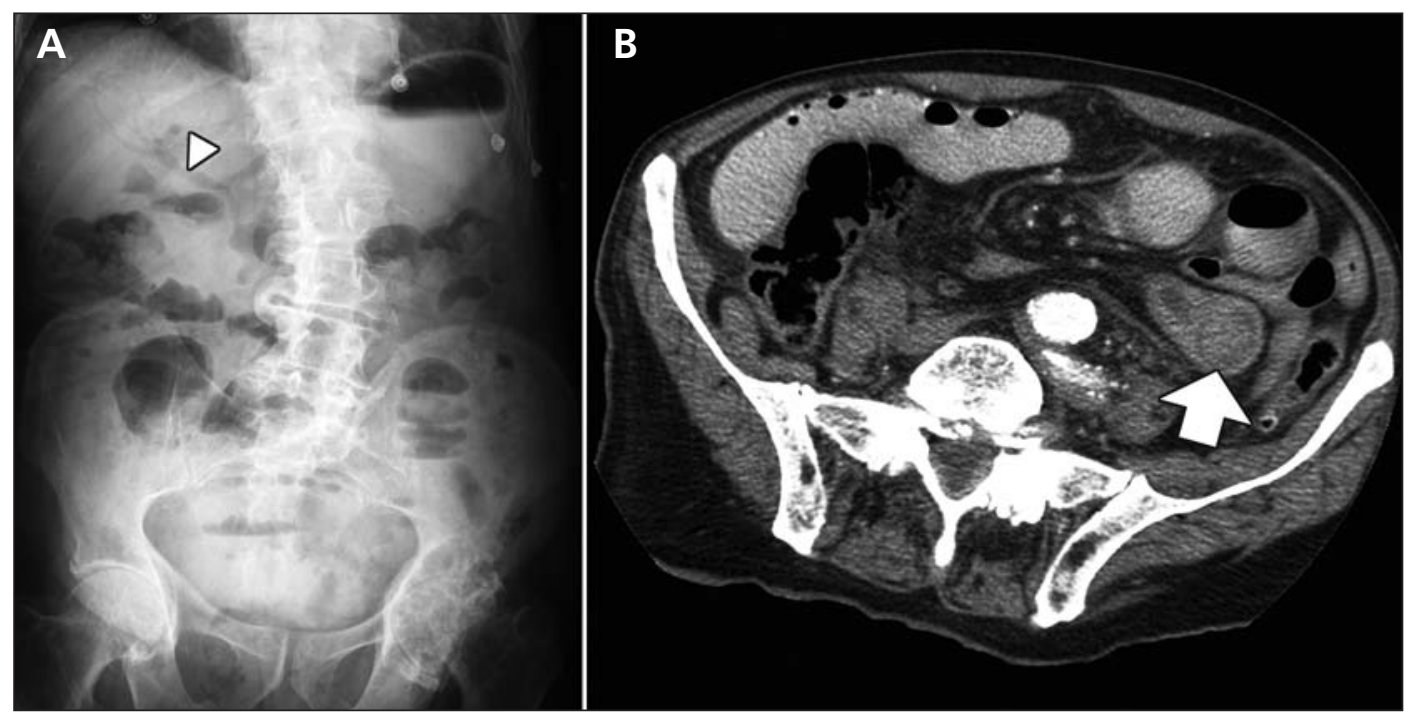

Figure 1: (A) Plain abdominal radiograph of a 90 -year-old man with acute retrosternal pain showing airfluid levels, predominantly in the small bowel, and pneumobilia (arrowhead). (B) Computed tomography scan showing an ectopic gallstone impacted in the lumen of the small bowel (arrow).

A 90-year-old man was admitted with acute-onset, pressing retrosternal pain and diffuse abdominal discomfort. Electrocardiography and cardiac troponin levels ruled out an acute coronary syndrome. Plain radiography of the abdomen (Figure 1A) showed multiple air-fluid levels and air in the biliary tree (pneumobilia). Computed tomography (CT) scanning showed an impacted ectopic gallstone, consistent with a diagnosis of gallstone ileus (Figure 1B). We removed a 4-cm gallstone from the jejunal lumen during explorative laparotomy; because of the patient's age, we chose not to repair his cholecystoduodenal fistula. After an initially uncomplicated postoperative course, he died of cardiac arrest 1 week after surgery.

Gallstone ileus, a rare complication of cholelithiasis, is caused by intestinal impaction of a gallstone that has migrated through a cholecystoenteric fistula. Mortality is high, up to $22.7 \%,{ }^{1}$ largely because most patients are elderly with associated comorbidities. The nonspecific clinical presentation tends to delay diagnosis and treatment. ${ }^{1}$ The classic radiologic sign of gallstone ileus is the Rigler triad (also called Rigler sign): pneumobilia, intestinal obstruction and an ectopic gallstone. ${ }^{2,3}$ Plain abdominal radiography can be valuable in the initial workup of a suspected small-bowel obstruction. However, gallstone ileus is easily missed on plain radiographs, because most gallstones are radiolucent and all 3 elements of the Rigler triad show up in only $15 \%$ of cases. ${ }^{2}$ Although formal guidelines are lacking, expert opinion supports the early use of abdominal CT scanning when gallstone ileus is suspected, with the Rigler triad seen in up to $80 \%$ of cases when CT is used. ${ }^{2,3}$ The decision to intervene surgically depends on the patient's clinical condition. Enterolithotomy alone (without cholecystectomy and fistula repair) is the preferred option in frail, older patients.

\section{References}

1. Ayantunde AA, Agrawal A. Gallstone ileus: diagnosis and management. World J Surg 2007;31:1292-7.

2. Lassandro F, Gagliardi N, Scuderi M, et al. Gallstone ileus analysis of radiological findings in 27 patients. Eur J Radiol 2004;50:23-9.

3. Lassandro F, Romano S, Ragozzino A, et al. Role of helical CT in diagnosis of gallstone ileus and related conditions. AJR Am J Roentgenol 2005;185:1159-65. 